\title{
. Optically Multiresponsive Heteroleptic Platinum Dithiolene Complex with Proton-Switchable Properties
}

\author{
${ }_{3}$ Salahuddin Attar, ${ }^{\dagger}$ Davide Espa ${ }^{\dagger}$ Flavia Artizzu, ${ }^{\dagger}$ Luca Pilia, ${ }^{\ddagger}$ Angela Serpe, ${ }^{\dagger}$ Maddalena Pizzotti, ${ }^{\S}$ \\ ${ }_{4}$ Gabriele Di Carlo, ${ }^{\S}$ Luciano Marchiò, ${ }^{\|}$and Paola Deplano* ${ }^{*} \perp_{(\mathbb{C}}$ \\ $5{ }^{\dagger}$ Dipartimento di Scienze Chimiche e Geologiche and Unità di Ricerca INSTM, Università di Cagliari, S.S. 554-Bivio per Sestu, \\ 6 I09042 Monserrato-Cagliari, Italy \\ $7{ }^{*}$ Dipartimento di Ingegneria Meccanica, Chimica e dei Materiali, Università di Cagliari, Via Marengo 2, I09123 Cagliari, Italy \\ $8{ }^{\$}$ Dipartimento di Chimica and Unità di Ricerca INSTM, Università di Milano, via Golgi 19, I20133 Milano, Italy \\ 9 "Dipartimento di Chimica, Università di Parma, Parco Area delle Scienze 17A, I43124 Parma, Italy \\ $10{ }^{\perp}$ Dipartimento di Fisica and Unità di Ricerca INSTM, Università di Cagliari, S.S. 554-Bivio per Sestu, I09042 Monserrato-Cagliari, \\ 11 Italy
}

12 S Supporting Information

13 ABSTRACT: Both linear- and nonlinear-optical proper14 ties of $\mathrm{Bu}_{4} \mathrm{~N}[\mathrm{Pt}(\mathrm{L} 1)(\mathrm{L} 2)] \quad\left(1 ; \mathrm{L} 1=\left[4^{\prime}, 5^{\prime}: 5,6\right][1,4]\right.$ 15 dithiino[2,3-b] quinoxaline-1', $3^{\prime}$ dithiolato; L2 = (R)- $\alpha$ 16 MBAdto dithiooxamidate, where $(R)-\alpha$-MBA $=(R)$ 17 (+)- $\alpha$-methylbenzyl) upon $\mathrm{HCl}$ addition at room temper18 ature change dramatically: the color turns from deep blue 19 to green; the luminescence switches from deep red to 20 green; the nonlinear-optical response (first hyperpolariz21 ability) increases by a factor of 12 . Thus, 1 behaves as a 22 unique multiresponsive optical switch whose properties 23 can be followed by the naked eye.

24 hanges of the linear-optical (LO; absorption and emission ${ }_{25} \cup$ of light $)^{1}$ as well nonlinear-optical (NLO) ${ }^{2}$ properties in 26 response to external stimuli are of current scientific interest and 27 for several applications in devices. ${ }^{3-5}$ Molecules suitable for 28 second-order NLO mostly consist of an electron-donor moiety 29 connected to an electron-acceptor moiety by a conjugated $\pi$ 30 bridge. $^{6}$ These chromophores show a typical donor-acceptor $31(\mathrm{D}-\mathrm{A})$ charge-transfer $(\mathrm{CT})$ transition falling in the low-energy 32 region. The two moieties may be conveniently functionalized to 33 enable the on/off switching of a property. ${ }^{7}$ Both forms are 34 required to be stable and easily switchable with a fast response 35 time. Among the possible molecular switching in D-A-type 36 chromophores, we have applied our efforts to a molecule where 37 the acceptor moiety $[(R)-\alpha$-MBAdto dithiooxamidate (L2), 38 where $(R)-\alpha$-MBA $=(R)-(+)-\alpha$-methylbenzyl] can easily 39 undergo proton exchange. The donor employed is $\left[4^{\prime}, 5^{\prime}: 5,6\right]$ $40[1,4]$ dithiino $[2,3-b]$ quinoxaline- $1^{\prime}, 3^{\prime}$ dithiolato (L1). This ligand 41 may provide the heteroleptic complex with an additional 42 functionality. In fact, the homoleptic platinum(II) complex 43 based on this ligand ${ }^{8}$ exhibits in solution at room-temperature a 44 proton-dependent emission at $572 \mathrm{~nm}$ well above the energy of 45 the lowest-energy absorption. ${ }^{9}$ The desired product was 46 prepared as summarized in Scheme S1 in the Supporting 47 Information (SI), where the characterization of 1 (Figures $48 \mathrm{~S} 1-\mathrm{S} 3)$, as well as X-ray crystallographic measurements and refinements (Tables S1 and S2 and Figures S4-S6) are 49 described.

The molecular structure of $\mathbf{1}$ comprises the complex anion 51 $[\mathrm{Pt}(\mathrm{L} 1)(\mathrm{L} 2)]^{-}$and the $\mathrm{Bu}_{4} \mathrm{~N}^{+}$cation (Figure 1).

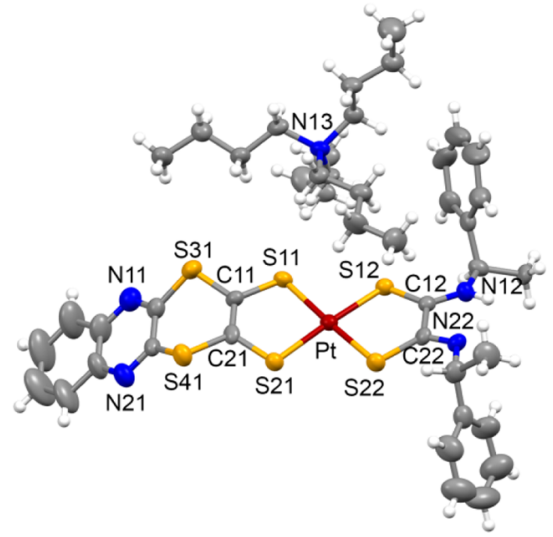

Figure 1. Molecular structure of 1 with thermal ellipsoids depicted at the $30 \%$ probability level.

The metal exhibits a square-planar geometry, with the $\mathrm{Pt}-\mathrm{S} 53$ bond distances derived from the quinoxaline ligand slightly 54 shorter than those derived from the dithiooxamidate ligand. This 55 is in agreement with the different charges of the two ligand 56 systems, 2- for the quinoxalinedithiolato system and 1- for the 57 dithiooxamidate system. Interestingly, the two SCN moieties of 58 the dithiooxamidate system present bond distances that reflect 59 monoprotonation of the $\mathrm{N}(12)$ atom. Accordingly, the $\mathrm{C}(22)-60$ $S(22)$ fragment exhibits a more pronounced thiolate feature, 61 whereas the $C(12)-S(12)$ fragment is characterized by a more 62 pronounced thione nature. As far as the LO properties are 63 concerned, $\mathbf{1}$ is characterized by a broad absorption in the visible 64 region with medium molar absorption coefficients $\left(\varepsilon=5.5 \times 10^{3} \quad 65\right.$ $\mathrm{M}^{-1} \mathrm{~cm}^{-1}$ ) centered at $595 \mathrm{~nm}$ in a $\mathrm{CH}_{3} \mathrm{CN}$ solution with a 66

Received: January 26, 2017 
67 shoulder at higher energy $(\sim 500 \mathrm{~nm})$ and a quite intense $(\varepsilon=$ $6810.3 \times 10^{3} \mathrm{M}^{-1} \mathrm{~cm}^{-1}$ ) absorption band at $375 \mathrm{~nm}$. Upon the 69 addition of $\mathrm{HCl}$, the color of the solution changes from deep blue 70 to green. A related substantial change in the absorption profile is 71 observed (Figure 2). In particular, the lowest absorption band

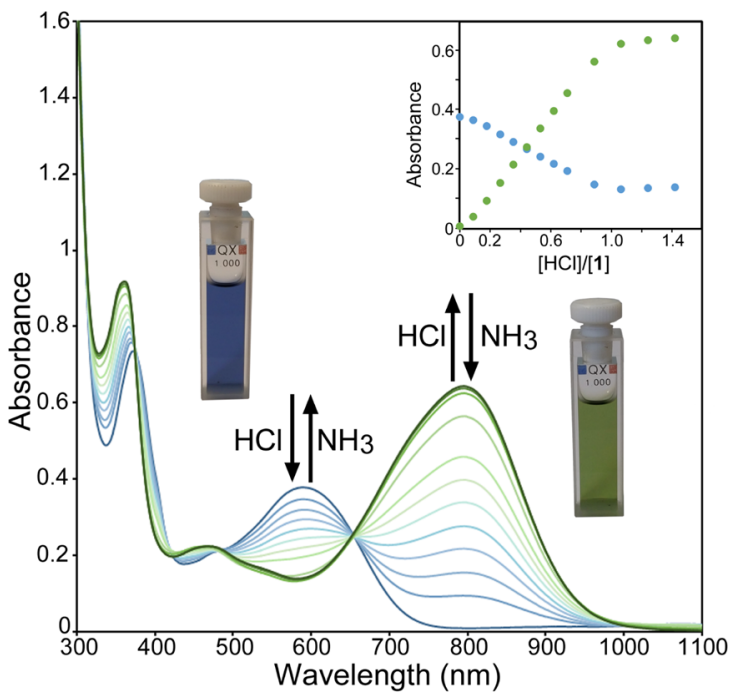

Figure 2. Variation of the absorption upon successive additions of $\mathrm{HCl}$ $\left(10 \mu \mathrm{L}, 10^{-3} \mathrm{M}\right)$ and $\mathrm{NH}_{3}\left(10 \mu \mathrm{L}, 10^{-3} \mathrm{M}\right)$ to a solution of 1 in $\mathrm{CH}_{3} \mathrm{CN}$ $\left(1 \mathrm{~mL}, 1 \times 10^{-4} \mathrm{M}\right)$. In the inset, plots of the absorbance values at 588 $\mathrm{nm}$ (blue) and $795 \mathrm{~nm}$ (green) against $[\mathrm{HCl}] /[\mathbf{1}]$ are reported.

72 disappears, whereas a new one is formed at higher wavelengths $73(800 \mathrm{~nm})$. The presence of well-defined isosbestic points (at 486 74 and $652 \mathrm{~nm}$ ) suggests that two absorbing species are involved in 75 the transformation process, which is complete for a 1:1 molar 76 ratio between $\mathrm{HCl}$ and 1 . The absorption intensity of the formed 77 species (2) does not increase upon further $\mathrm{HCl}$ addition (see the 78 inset in Figure 2).

79 Previous studies by Campagna, Lanza, and co-workers. ${ }^{10}$ 80 showed that platinum homoleptic complexes coordinated to $81 \mathrm{~N}, N^{\prime}$-dialkyldithiooxamidate ligands formed tight-contact ion 82 pairs with $\mathrm{HX}(\mathrm{X}=\mathrm{Cl}, \mathrm{Br}, \mathrm{I})$, where the $\mathrm{N} \cdot \cdot \mathrm{H} \cdot \mathrm{X}$ interactions play 83 a role in stabilizing the ion-pair species. Also in the present case, $84 \mathrm{HCl}$ addition to $\mathbf{1}$ solutions results in protonation of the $\mathrm{N}$ atom 85 on $\mathrm{L} 2$, and the $\mathrm{N}-\mathrm{H} \cdot \cdot \mathrm{Cl}$ interactions significantly affect the 86 properties of the formed complex anion, $2(\mathrm{X}=\mathrm{Cl})$, as supported 87 by DFT calculations (vide infra and Figures S7-S10). The trend 88 observed in the spectra of $\mathbf{1}$ upon the addition of different halo 89 acids is reported in Figure S11. Density functional theory (DFT) 90 and time-dependent DFT (TD-DFT) ${ }^{1-17}$ calculations in 91 $\mathrm{CH}_{3} \mathrm{CN}$ allow one to relate the low-frequency peaks mainly to 92 a highest occupied molecular orbital (HOMO)-lowest un93 occupied molecular orbital (LUMO) transition (Figures 3 and $94 \mathrm{~S} 9$ and S10). A predominant contribution to the HOMO is 95 provided by a mixture of $\pi$-dithiolate and metal orbitals, while a $96 \pi^{*}$-dithiooxamidate orbital gives a predominant contribution to 97 the LUMO (LL'CT = ligand-to-ligand charge transfer with some 98 metal contribution). When $\mathbf{1}$ interacts with $\mathrm{HCl}$, the $\mathrm{HOMO}$ 99 energy is not affected while the LUMO is stabilized in agreement 100 with the observed shift to longer wavelength of the CT band. It is 101 worth noting that the LUMO +1 , a $\pi$ orbital of the quinoxaline 102 moiety, is raised in energy.

103 Upon irradiation in the visible region at $450 \mathrm{~nm}$, the complex f4
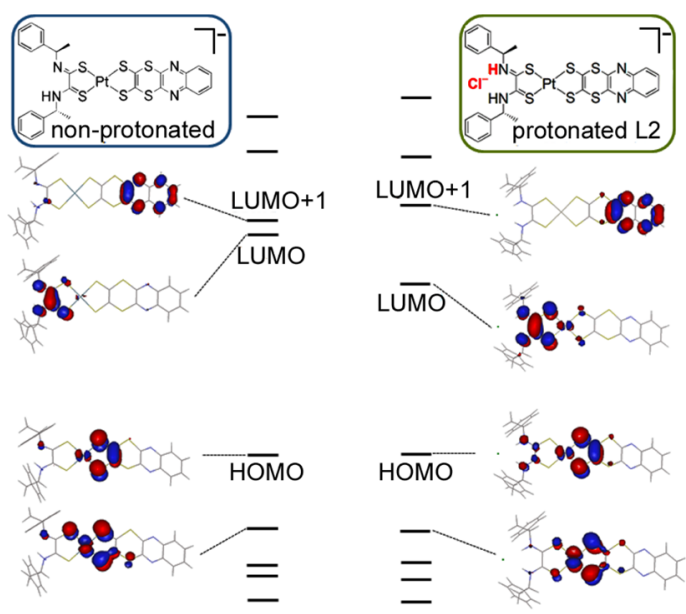

Figure 3. Frontier molecular orbitals of $\mathbf{1}$ (left) and $\mathbf{2}$ (right). Calculations were performed with the PCM method in acetonitrile, B3LYP/6-31+G(d)-SDD. ${ }^{11}$

solution at room temperature (Figure 4). The emission color $105 \mathrm{f} 4$ can be tuned from deep red $(715 \mathrm{~nm})$ to bright green $(570 \mathrm{~nm}) 106$

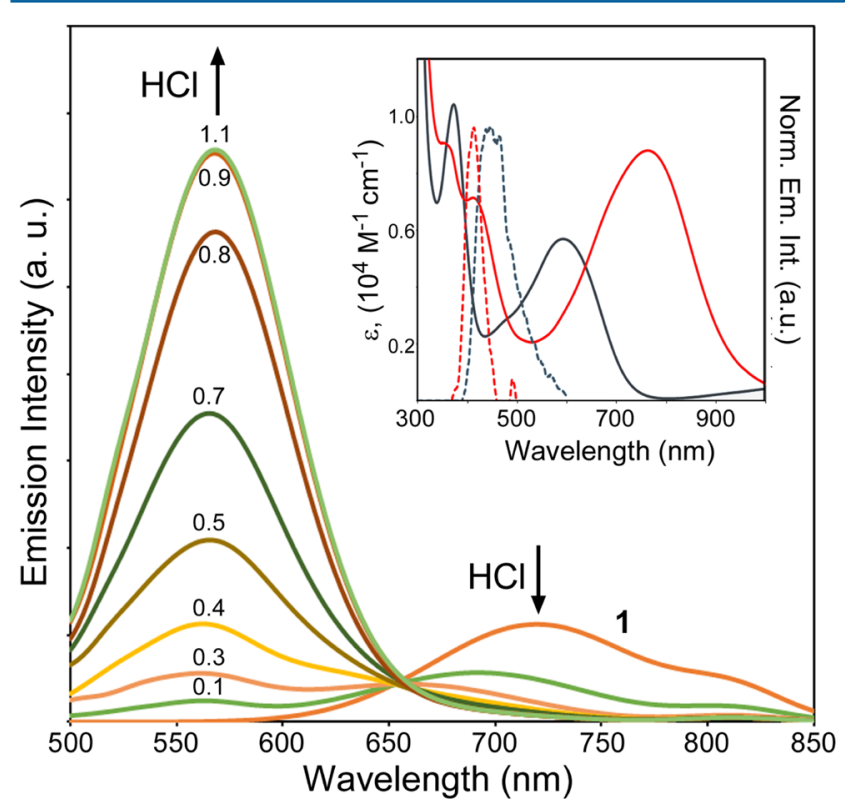

Figure 4. Emission change upon successive additions of $\mathrm{HCl}(10 \mu \mathrm{L}$, $\left.10^{-2} \mathrm{M}\right)$ to a solution of 1 in $\mathrm{CH}_{3} \mathrm{CN}\left(1.5 \mathrm{~mL}, 5 \times 10^{-4} \mathrm{M}\right)$. Molar ratios $[\mathrm{HCl}] /[1]$ are indicated. The excitation wavelength was $450 \mathrm{~nm}$. In the inset, the excitation spectra (dashed lines) are compared to the absorption spectra (solid lines) in a $\mathrm{CH}_{3} \mathrm{CN}$ solution of $\mathbf{1}$ (black) and $\mathbf{2}$ (red).

upon the addition of 1 equiv of $\mathrm{HCl}$, while the subsequent 107 addition of $\mathrm{NH}_{3}$ totally quenches the green band and restores the 108 initial conditions (see Figure S12). Interestingly, both of these 109 emissions are dependent on the excitation wavelength (see the 110 inset in Figure 4), and no photoluminescence is detected upon 111 excitation of the lowest absorption band corresponding to the 112 HOMO-LUMO transition as well as in the UV part of the 113 absorption spectrum. These results may suggest an unusual anti- 114 Kasha-Vavilov behavior ${ }^{18-20}$ for $\mathbf{1}$ in the both unprotonated and 115 protonated forms $^{21}$ (see also Figure S13).

A similar behavior was recently found for the homoleptic 117 platinum complex with ligand $\mathrm{L} 1,\left[\mathrm{Pt}(\mathrm{L} 1)_{2}\right]^{-8}$. In this last case, 118 
119 irradiation at $420 \mathrm{~nm}$ under neutral conditions in a solution at 120 room temperature yields an emission peak at $572 \mathrm{~nm}$, which is 121 well above the energy to the lowest absorption peak at $1085 \mathrm{~nm}$ 122 associated with the $\mathrm{HOMO}-1 \rightarrow$ SOMO transition. Emission 123 was attributed to the HOMO- $1 \leftarrow$ LUMO transition, involving 124 orbitals localized on the quinoxaline moiety. On the other hand, 125 the homoleptic $\left[\mathrm{Pt}(\mathrm{HL} 2)_{2}\right]$ complex is nonluminescent in the 126 neutral form. This complex becomes emissive at $700 \mathrm{~nm}$ upon $127 \mathrm{HCl}$ addition as a contact ion pair formulated as $\left[\mathrm{Pt}\left(\mathrm{H}_{2}-\mathrm{R}_{2}\right.\right.$ $\left.128 \mathrm{dto})_{2}{ }^{2+}(\mathrm{Cl})_{2}\right] .^{22,23}$ Reversibility of this property is also observed 129 upon $\mathrm{NH}_{3}$ addition. Therefore, a comparison of the emissive 130 properties of 1 with respect to the corresponding homoleptic 131 complexes as well as the sequence of molecular orbitals (Figures 1323 and S10) suggests that the process originates mainly from 133 intraligand charge-transfer (ILCT) transitions involving L1 134 orbitals of the dithiolate moiety, with some metal contribution, 135 and the ligand periphery localized on the quinoxaline moiety $136(\mathrm{LUMO}+1)$ in both $\mathbf{1}$ and 2 , similarly to $\left[\mathrm{Pt}(\mathrm{L1})_{2}\right]^{-}$. In the 137 present case, L2 acts as a reversible proton acceptor, and the 138 synergistic combination of the two ligands L1 and L2 allows 139 tuning of the emission color of L1 through the proton-switchable 140 properties of L2. The rather low quantum yields evaluated 141 through the relative method $\left(6.4 \times 10^{-5}\right.$ for 1 and $1.4 \times 10^{-4}$ for 1422 ) and the room temperature decay times estimated from 143 spectral data falling in the picosecond range (14 ps for 1 and 4 ps 144 for 2; see the SI and Table S3) point out that the radiative decay 145 channel in both $\mathbf{1}$ and $\mathbf{2}$ is strongly quenched by other 146 deactivation pathways. Therefore, it must be underlined that 147 the term "anti-Kasha" emission is herein used with caution to 148 describe an apparent phenomenon related to the observed 149 spectral features. Transient absorption experiments currently 150 underway will help to clarify the peculiar photocycle leading to 151 the apparent anti-Kasha emission in this complex.

152 In addition to these LO properties, 1 exhibits also proton153 switchable NLO properties. Protonation-deprotonation NLO 154 switches in solution are commonly studied by the hyper155 Rayleigh-scattering (HRS) technique working at $1064 \mathrm{~nm}$ 156 incident wavelength, which, however, suffers the limitation of 157 possible overestimation of the value of the quadratic hyper158 polarizability due to resonance. ${ }^{24-26}$ To achieve more reliable 159 data, the electric-field-induced second-harmonic-generation 160 (EFISH) technique was employed to determine the second161 order NLO response of the molecular chromophore 1 in $\mathrm{CHCl}_{3}$ 162 solutions, working at a nonresonant $1907 \mathrm{~nm}$ incident 163 wavelength, from which $\mu \beta_{\lambda}$ can be obtained, ${ }^{27}$ (see the SI for 164 experimental details). ${ }^{28}$ More recently, a second-order NLO 165 response by the EFISH technique has been reported for 166 protonation-deprotonation NLO switches applied to organic ${ }^{29}$ 167 and organometallic ${ }^{30}$ compounds. A remarkable $\mu \beta_{1907}$ value 168 increase for 1 by a factor of 4 (from $-735 \times 10^{-48}$ esu for 1 to $169-2980 \times 10^{-48}$ esu for 2 ) is obtained. By taking into 170 consideration the calculated $\mu$ value for 1 and 2 (12.6 and 3.9 $171 \mathrm{D}$, respectively), the obtained $\beta$ values show an increase by a 172 factor of 12 ( 60 and $735 \times 10^{-30}$ esu for 1 and 2 , respectively). It 173 is worth noting that the $\mu \beta_{\lambda}$ value determined on the $1 \cdot \mathrm{HCl}$ 174 solution after $\mathrm{NH}_{3}$ addition suggests that the NLO-phore $\mathbf{1}$ is 175 restored. The negative sign of $\mu \beta_{\lambda}$ values is in agreement with a 176 decrease of the dipolar moments in the excited states, as reflected 177 by the negative solvatochromism observed for the involved CT 178 peaks (Figure S14). Similar behavior was observed for $179 \mathrm{M}$ (diimine)(dithiolate) complexes, ${ }^{31}$ that have been largely 180 investigated by Eisenberg's group and others for their $\mathrm{NLO}^{32-34}$ 181 and luminescent properties ${ }^{32}$ and as sensitizers or photocatalysts for light-to-chemical energy conversion. ${ }^{35-37}$ Several organ- 182 ic $^{24-26,38-41}$ and organometallic ${ }^{30,42-47}$ molecules based on 183 $\mathrm{D}-\pi$-A moieties have been shown to undergo a variation of 184 hyperpolarizability upon variation of the $\mathrm{D}-\mathrm{A}$ strength or of the 185 $\pi$ bridge induced by external stimuli, including protonation. 186 Similarly, proton-switchable emission has been found. ${ }^{18,48,49} 187$ Remarkably, in the case under discussion, color, second-order 188 NLO response, and emission all undergo switching upon 189 protonation.

190

In conclusion, $\mathbf{1}$ behaves as a versatile multiresponsive optical 191 switch. Coordination to the metal ion of L1 and L2, each of them 192 a carrier of functionality, in a square-planar geometry allows one 193 to reach a favorable arrangement for second-order NLO and for 194 reversible interactions with $\mathrm{HCl}$ through $\mathrm{L} 2$. These interactions 195 affect both the LO and NLO properties. This peculiarity is 196 accompanied by an uncommon behavior of the emission 197 properties of $\mathbf{1}$. Thus, $\mathbf{1}$ represents a unique candidate that 198 should stimulate interest in deepening its remarkable properties 199 both for pure scientific reasons and for potential applications as a 200 multiresponsive optical switch whose changes, accompanied by 201 color tuning, can be followed by the naked eye.

202

\section{ASSOCIATED CONTENT}

203

\section{S Supporting Information}

204

The Supporting Information is available free of charge on the 205 ACS Publications website at DOI: 10.1021/acs.inorg- 206 chem.7b00238.

207

Preparation and characterization of 1, details on X-ray 208 crystallography, DFT and TD-DFT computational 209 studies, additional absorption and emission spectra 210 including those of L1, photophysical parameter evaluation, 211 details on NLO measurements, and solvatochromism 212 (PDF)

CCDC 1497428 contains the supplementary crystallographic 215 data for this paper. These data can be obtained free of charge via 216 www.ccdc.cam.ac.uk/data_request/cif, or by emailing data_ 217 request@ccdc.cam.ac.uk, or by contacting The Cambridge 218 Crystallographic Data Centre, 12 Union Road, Cambridge 219 CB2 1EZ, UK; fax: +44 1223336033.

\section{AUTHOR INFORMATION}

\section{Corresponding Author}

*E-mail: deplano@unica.it. Phone: +39070675 4680.

\section{ORCID $\odot$}

Angela Serpe: 0000-0002-3476-0636

Paola Deplano: 0000-0002-8861-8619

\section{Notes}

The authors declare no competing financial interest.

\section{ACKNOWLEDGMENTS}

The authors warmly thank Prof. A. Cannizzo for helpful 230 discussion regarding anti-Kasha behavior and Prof. S. Lanza 231 regarding ligand L2 features. This research was supported by 232 Fondazione Banco di Sardegna. Thanks are also due to COST 233 Action CM1202, PERSPECT-H2O.

\section{REFERENCES}

(1) You, J.; Kim, J.; Park, T.; Kim, B.; Kim, E. Highly Fluorescent 236 Conjugated Polyelectrolyte Nanostructures: Synthesis, Self-Assembly, 237 and $\mathrm{Al}^{3+}$ Ion Sensing. Adv. Funct. Mater. 2012, 22, 1417-1424. 
239 (2) van Bezouw, S.; Campo, J.; Lee, S.-H.; Kwon, O.-P.; Wenseleers, 240 W. Organic Compounds with Large and High-Contrast $\mathrm{pH}$-Switchable 241 Nonlinear Optical Response. J. Phys. Chem. C 2015, 119, 21658-21663. 242 (3) Mori, T.; Okamoto, K.; Endo, H.; Hill, J. P.; Shinoda, S.; 243 Matsukura, M.; Tsukube, H.; Suzuki, Y.; Kanekiyo, Y.; Ariga, K. 244 Mechanical Tuning of Molecular Recognition To Discriminate the 245 Single-Methyl-Group Difference between Thymine and Uracil. J. Am. 246 Chem. Soc. 2010, 132, 12868-12870.

247 (4) Campagnola, P. Second harmonic generation imaging microscopy: 248 Applications to diseases diagnostics. Anal. Chem. 2011, 83, 3224-3231. 249 (5) Best, Q. A.; Sattenapally, N.; Dyer, D. J.; Scott, C. N.; McCarroll, 250 M. E. pH-Dependent Si-Fluorescein Hypochlorous Acid Fluorescent 251 Probe: Spirocycle Ring-Opening and Excess Hypochlorous Acid252 Induced Chlorination. J. Am. Chem. Soc. 2013, 135, 13365-13370.

253 (6) Goovaerts, E.; Wenseleers, W. E.; Garcia, M. H.; Cross, G. H. 254 Handbook of Advanced Electronic and Photonic Materials and Devices. 255 In Nonlinear Optical Materials; Nalwa, H. S., Ed.; Academic Press: New 256 York, 2001; Vol. 9.

257 (7) Asselberghs, I.; Clays, K.; Persoons, A.; Ward, M. D.; McCleverty, J. 258 Switching of molecular second-order polarisability in solution. J. Mater. 259 Chem. 2004, 14, 2831-2839.

260 (8) Attar, S.; Espa, D.; Artizzu, F.; Mercuri, M. L.; Serpe, A.; Sessini, E.; 261 Concas, G.; Congiu, F.; Marchiò, L.; Deplano, P. A Platinum-Dithiolene 262 Monoanionic Salt Exhibiting Multiproperties, Including Room263 Temperature Proton-Dependent Solution Luminescence. Inorg. Chem. 264 2016, 55, 5118-5126.

265 (9) Kasha, M. Characterization of electronic transitions in complex 266 molecules. Discuss. Faraday Soc. 1950, 9, 14-19.

267 (10) Giannetto, A.; Puntoriero, F.; Barattucci, A.; Lanza, S.; Campagna, $268 \mathrm{~S}$. Tight-contact ion pairs involving $\mathrm{Pt}(\mathrm{II})$ dithiooxamide complexes: 269 The acid-base reactions between hydrohalogenated ion-paired com270 plexes and pyridine. Inorg. Chem. 2009, 48, 10397-10404.

271 (11) Becke, A. D. Density-functional exchange-energy approximation 272 with correct asymptotic behavior. Phys. Rev. A: At., Mol., Opt. Phys. 1988, 273 38, 3098-3100.

274 (12) Becke, A. D. Density-functional thermochemistry. III. The role of 275 exact exchange. J. Chem. Phys. 1993, 98, 5648-5652.

276 (13) Fuentealba, P.; Preuss, H.; Stoll, H.; Von Szentpaly, L. A proper 277 account of core-polarization with pseudopotentials: single valence278 electron alkali compounds. Chem. Phys. Lett. 1982, 89, 418-422.

279 (14) Cao, X. Y.; Dolg, M. Segmented contraction scheme for small280 core lanthanide pseudopotential basis sets. J. Mol. Struct.: THEOCHEM 281 2002, 581, 139-147.

282 (15) Schwerdtfeger, P.; Dolg, M.; Schwarz, W. H. E.; Bowmaker, G. A.; 283 Boyd, P. D. W. Relativistic effects in gold chemistry. I. Diatomic gold 284 compounds. J. Chem. Phys. 1989, 91, 1762-1774.

285 (16) Casida, M. E.; Jamorski, C.; Casida, K. C.; Salahub, D. R. 286 Molecular excitation energies to high-lying bound states from time287 dependent density-functional response theory: Characterization and 288 correction of the time-dependent local density approximation ionization 289 threshold. J. Chem. Phys. 1998, 108, 4439-4449.

290 (17) Tomasi, J.; Mennucci, B.; Cammi, R. Quantum mechanical 291 continuum solvation models. Chem. Rev. 2005, 105, 2999-3093.

292 (18) Park, Y. I.; Postupna, O.; Zhugayevych, A.; Shin, H.; Park, Y.-S.; 293 Kim, B.; Yen, H.-J.; Cheruku, P.; Martinez, J. S.; Park, J. W.; Tretiak, S.; 294 Wang, H.-L. A new pH sensitive fluorescent and white light emissive 295 material through controlled intermolecular charge transfer. Chem. Sci. 296 2015, 6, 789-797.

297 (19) Tseng, H.-W.; Shen, J.-Y.; Kuo, T.-Y.; Tu, T.-S.; Chen, Y.-A.; 298 Demchenko, A. P.; Chou, P.-T. Excited-state intramolecular proton299 transfer reaction demonstrating anti-Kasha behavior. Chem. Sci. 2016, 7, $300655-665$.

301 (20) Scuppa, S.; Orian, L.; Donoli, A.; Santi, S.; Meneghetti, M. Anti302 Kasha's rule fluorescence emission in (2-ferrocenyl)indene generated by 303 a twisted intramolecular charge-transfer (TICT) process. J. Phys. Chem. 304 A 2011, 115, 8344-8349.

305 (21) The emission behavior of the free ligand L1 and its protonated 306 form as well as the related discussion are reported in Figure S13 to address the concerns of impurities due to possible ligand dissociation 307 upon the addition of acid.

(22) Nastasi, F.; Puntoriero, F.; Palmeri, N.; Cavallaro, S.; Campagna, 309 S.; Lanza, S. Solid-state luminescence switching of platinum(ii) 310 dithiooxamide complexes in the presence of hydrogen halide and 311 amine gases. Chem. Commun. 2007, 4740-4742.

(23) Rosace, G.; Giuffrida, G.; Saitta, M.; Guglielmo, G.; Campagna, S.; 313 Lanza, S. Luminescence Properties of Platinum(II) Dithiooxamide 314 Compounds. Inorg. Chem. 1996, 35, 6816-6822.

(24) Mançois, F.; Pozzo, J.-L.; Pan, J.; Adamietz, F.; Rodriguez, V.; 316 Ducasse, L.; Castet, F.; Plaquet, A.; Champagne, B. Two-way molecular 317 switches with large nonlinear optical contrast. Chem. - Eur. J. 2009, 15, 318 $2560-2571$.

319

(25) Castet, F.; Champagne, B.; Pina, F.; Rodriguez, V. A multistate 320 $\mathrm{pH}$-triggered nonlinear optical switch. ChemPhysChem 2014, 15, 2221- 321 2224.

322

(26) Asselberghs, I.; Flors, C.; Ferrighi, L.; Botek, E.; Champagne, B.; 323 Mizuno, H.; Ando, R.; Miyawaki, A.; Hofkens, J.; Van der Auweraer, M.; 324 Clays, K. Second-harmonic generation in GFP-like proteins. J. Am. 325 Chem. Soc. 2008, 130, 15713-15719.

(27) $\mu$ is the ground-state dipole moment, $\beta_{\lambda}$ is the projection along the 327 dipole moment axis of the vectorial component $\beta_{\mathrm{VEC}}$ of the tensorial 328 quadratic hyperpolarizability, and $\lambda$ is the fundamental wavelength of the 329 incident photons.

330

(28) (a) Alain, V.; Blanchard-Desce, M.; Ledoux-Rak, I.; Zyss, J. 331 Amphiphilic polyenic push-pull chromophores for nonlinear optical 332 applications. Chem. Commun. 2000, 353-354. (b) Valore, A.; Cariati, E.; 333 Dragonetti, C.; Righetto, S.; Roberto, D.; Ugo, R.; De Angelis, F.; 334 Fantacci, S.; Sgamellotti, S.; Macchioni, A.; Zuccaccia, D. Cyclo- 335 metalated Ir $^{\text {III }}$ Complexes with Substituted 1,10-Phenanthrolines: A 336 New Class of Efficient Cationic Organometallic Second-Order NLO 337 Chromophores-. Chem. - Eur. J. 2010, 16, 4814-4825. (c) Tessore, F.; 338 Cariati, E.; Cariati, F.; Roberto, D.; Ugo, R.; Mussini, P.; Zuccaccia, C.; 339 Macchioni, A. The Role of Ion Pairs in the Second-Order NLO 340 Response of 4-X-1-Methylpiridinium Salts. ChemPhysChem 2010, 11, 341 495-507. (d) Colombo, A.; Locatelli, D.; Roberto, D.; Tessore, F.; Ugo, 342 R.; Cavazzini, M.; Quici, S.; De Angelis, F.; Fantacci, S.; Ledoux-Rak, I.; 343 Tancrez, N.; Zyss, J. New [(D-terpyridine)-Ru-(D or A-terpyridine)][4- 344 $\left.\mathrm{EtPhCO}_{2}\right]_{2}$ complexes $(\mathrm{D}=$ electron donor group; $\mathrm{A}=$ electron acceptor 345 group) as active second-order non linear opticalchromophores. Dalton 346 Trans. 2012, 41, 6707-6714.

(29) (a) Nisic, F.; Colombo, A.; Dragonetti, C.; Fontani, M.; 348 Marinotto, D.; Righetto, S.; Roberto, D.; Williams, J. A. G. Highly 349 efficient acido-triggered reversible luminescent and nonlinear optical 350 switch based on 5- $\pi$-delocalized-donor-1,3-di(2-pyridyl)benzenes. J. 351 Mater. Chem. C 2015, 3, 7421-7427. (b) Cariati, E.; Botta, C.; Danelli, 352 S. G.; Forni, A.; Giaretta, A.; Giovanella, U.; Lucenti, E.; Marinotto, D.; 353 Righetto, S.; Ugo, R. Solid state and solution fine tuning of the linear and 354 nonlinear optical properties of (2-pyrene-1-yl-vinyl)pyridine by 355 protonation-deprotonation reactions. Chem. Commun. 2014, 50, 356 14225-14228. (c) Cariati, E.; Dragonetti, C.; Lucenti, E.; Nisic, F.; 357 Righetto, S.; Roberto, D.; Tordin, E. An acido-triggered reversible 358 luminescent and nonlinear optical switch based on a substituted 359 styrylpyridine: EFISH measurements as an unusual method to reveal a 360 protonation-deprotonation NLO contrast. Chem. Commun. 2014, 50, 361 $1608-1610$.

362

(30) Boixel, J.; Guerchais, V.; Le Bozec, H.; Chantzis, A.; Jacquemin, 363 D.; Colombo, A.; Dragonetti, C.; Marinotto, D.; Roberto, D. Sequential 364 double second-order nonlinear optical switch by an acido-triggered 365 photochromic cyclometallated platinum(II) complex. Chem. Commun. 366 2015, 51, 7805-7808.

(31) Cummings, S. D.; Eisenberg, R. Tuning the Excited-State 368 Properties of Platinum(II) Diimine Dithiolate Complexes. J. Am. Chem. 369 Soc. 1996, 118, 1949-1960.

(32) Cummings, S. D.; Eisenberg, R. Progress in Inorganic Chemistry; 371 Wiley: New York, 2004; Vol. 52, Chapter 6.

(33) Cummings, S. D.; Cheng, L.-T.; Eisenberg, R. Metalloorganic 373 Compounds for Nonlinear Optics: Molecular Hyperpolarizabilities of 374 
$375 \mathrm{M}$ (diimine) (dithiolate) Complexes ( $\mathrm{M}=\mathrm{Pt}, \mathrm{Pd}, \mathrm{Ni})$. Chem. Mater. 376 1997, 9, 440-450.

377 (34) Mitsopoulou, C. A. Identifying of charge-transfer transitions and 378 reactive centers in $\mathrm{M}$ (diimine) (dithiolate) complexes by DFT 379 techniques. Coord. Chem. Rev. 2010, 254, 1448-1456.

380 (35) Islam, A.; Sugihara, H.; Hara, K.; Singh, L. P.; Katoh, R.; Yanagida, 381 M.; Takahashi, Y.; Murata, S.; Arakawa, H. G.; Fujihashi, G. Dye 382 Sensitization of Nanocrystalline Titanium Dioxide with Square Planar 383 Platinum(II) Diimine Dithiolate Complexes. Inorg. Chem. 2001, 40, 384 5371-5380.

385 (36) Geary, E. A. M.; Yellowlees, L. J.; Jack, L. A.; Oswald, I. D. H.; 386 Parsons, S.; Hirata, N.; Durrant, J. R.; Robertson, N. Synthesis, 387 Structure, and Properties of [Pt(II) (diimine) (dithiolate)] Dyes with 388 3,3'-, 4,4'-, and 5,5'-Disubstituted Bipyridyl: Applications in Dye389 Sensitized Solar Cells. Inorg. Chem. 2005, 44, 242-250.

390 (37) Zhang, J.; Du, P.; Schneider, J.; Jarosz, J.; Eisenberg, R. 391 Photogeneration of Hydrogen from Water Using an Integrated System 392 Based on $\mathrm{TiO}_{2}$ and Platinum(II) Diimine Dithiolate Sensitizers. J. Am. 393 Chem. Soc. 2007, 129, 7726-7727.

394 (38) Aubert, V.; Guerchais, V.; Ishow, E.; Hoang-Thi, K.; Ledoux, I.; 395 Nakatani, K.; Le Bozec, H. Efficient photoswitching of the nonlinear 396 optical properties of dipolar photochromic zinc(II) complexes. Angew. 397 Chem., Int. Ed. 2008, 47, 577-580.

398 (39) Bogdan, E.; Plaquet, A.; Antonov, L.; Rodriguez, V.; Ducasse, L.; 399 Champagne, B.; Castet, F. Solvent effects on the second-order nonlinear 400 optical responses in the keto-enol equilibrium of a 2-hydroxy-1401 naphthaldehyde derivative. J. Phys. Chem. C 2010, 114, 12760-12768. 402 (40) Szaloki, G.; Alévêque, O.; Pozzo, J. L.; Hadji, R.; Levillain, E.; 403 Sanguinet, L. Indolinooxazolidine: A Versatile Switchable Unit. J. Phys. 404 Chem. B 2015, 119, 307-315.

405 (41) Bondu, F.; Hadji, R.; Szalóki, G.; Alévêque, O.; Sanguinet, L.; 406 Pozzo, J. L.; Cavagnat, D.; Buffeteau, T.; Rodriguez, V. Huge Electro-/ 407 Photo-/Acidoinduced Second-Order Nonlinear Contrasts From Multi408 addressable Indolinooxazolodine. J. Phys. Chem. B 2015, 119, 67584096765 .

410 (42) Asselberghs, I.; Clays, K.; Persoons, A.; McDonagh, A. M.; Ward, 411 M. D.; Mc Cleverty, J. A. In situ reversible electrochemical switching of 412 the molecular first hyperpolarizability. Chem. Phys. Lett. 2003, 368, 408413411.

414 (43) Boubekeur-Lecaque, L.; Coe, B. J.; Harris, J. A.; Helliwell, M.; 415 Asselberghs, I.; Clays, K.; Foerier, S.; Verbiest, T. Incorporation of 416 Amphiphilic Ruthenium(II) Ammine Complexes into Langmuir417 Blodgett Thin Films with Switchable Quadratic Nonlinear Optical 418 Behavior. Inorg. Chem. 2011, 50, 12886-12899.

419 (44) Di Bella, S.; Oliveri, I. P.; Colombo, A.; Dragonetti, C.; Righetto, 420 S.; Roberto, D. An unprecedented switching of the second-order 421 nonlinear optical response in aggregate bis(salicylaldiminato)zinc(II) 422 Schiff-base complexes. Dalton Trans. 2012, 41, 7013-7016.

423 (45) Zhang, Y. R.; Castet, F.; Champagne, B. Theoretical investigation 424 of the first hyperpolarizability redox-switching in a ruthenium complex. 425 Chem. Phys. Lett. 2013, 574, 42-46.

426 (46) Wang, W. Y.; Ma, N. N.; Sun, S. L.; Qiu, Y. Q. Impact of redox 427 stimuli on ferrocene-buckybowl complexes: switchable optoelectronic 428 and nonlinear optical properties. Organometallics 2014, 33, 3341-3352. 429 (47) Beaujean, P.; Bondu, F.; Plaquet, A.; Garcia-Amorós, J.; Cusido, J.; 430 Raymo, F. M.; Castet, F.; Rodriguez, V.; Champagne, B. Oxazines: A 431 New Class of Second-Order Nonlinear Optical Switches. J. Am. Chem. 432 Soc. 2016, 138, 5052-5062.

433 (48) Alam, P.; Kaur, G.; Chakraborty, S.; Roy Choudhury, A. R.; 434 Laskar, I. R. Aggregation induced phosphorescence" active "rollover" 435 iridium(III) complex as a multi-stimuli-responsive luminescence 436 material. Dalton Trans. 2015, 44, 6581-6592.

437 (49) Pilato, R. S.; van Houten, K. A.; Progress in Inorganic Chemistry; 438 Stiefel, E. I., Ed.; Wiley: New York, 2004; Vol. 52, Chapter 7, pp 369439397. 